Original Full Length Article

\title{
Calcium response in osteocytic networks under steady and oscillatory fluid flow
}

\author{
X. Lucas Lu ${ }^{\text {a,b }}$, Bo Huo ${ }^{\text {a,c }}$, Miri Park ${ }^{\text {a,b }}$, X. Edward Guo ${ }^{\text {a,* }}$ \\ a Bone Bioengineering Laboratory, Department of Biomedical Engineering, Columbia University, New York, NY 10027, USA \\ ${ }^{\mathrm{b}}$ Department of Mechanical Engineering, University of Delaware, Newark, DE 19716, USA \\ ' Institute of Mechanics, Chinese Academy of Sciences, Beijing 100190, PR China
}

\section{A R T I C L E I N F O}

Article history:

Received 1 December 2011

Revised 4 May 2012

Accepted 5 May 2012

Available online 28 June 2012

Edited by J. Aubin

\section{Keywords}

Osteocyte

Mechanotransduction

Calcium response

Fluid flow

Steady

Oscillatory

\begin{abstract}
A B S T R A C T
The fluid flow in the lacunar-canalicular system of bone is an essential mechanical stimulation on the osteocyte networks. Due to the complexity of human physical activities, the fluid shear stress on osteocyte bodies and processes consists of both steady and oscillatory components. In this study, we investigated and compared the intracellular calcium $\left(\left[\mathrm{Ca}^{2+}\right]_{\mathrm{i}}\right)$ responses of osteocytic networks under steady and oscillatory fluid flows. An in vitro osteocytic network was built with MLO-Y4 osteocyte-like cells using micro-patterning techniques to simulate the in vivo orderly organization of osteocyte networks. Sinusoidal oscillating fluid flow or unidirectional steady flow was applied on the cell surface with 2 Pa peak shear stress. It was found that the osteocytic networks were significantly more responsive to steady flow than to oscillatory flow. The osteocytes can release more calcium peaks with higher magnitudes at a faster speed under steady flow stimulation. The $\left[\mathrm{Ca}^{2+}\right]_{\mathrm{i}}$ signaling transients under the steady and oscillatory flows have significantly different spatiotemporal characters, but a similar responsive percentage of cells. Further signaling pathway studies using inhibitors showed that endoplasmic reticulum (ER) calcium store, extracellular calcium source, ATP, $\mathrm{PGE}_{2}$ and NO related pathways play similar roles in the $\left[\mathrm{Ca}^{2+}\right]_{i}$ signaling of osteocytes under either steady or oscillating flow. The spatiotemporal characteristics of $\left[\mathrm{Ca}^{2+}\right]_{i}$ transients under oscillating fluid flow are affected more profoundly by pharmacological treatments than under the steady flow. Our findings support the hypothesis that the $\left[\mathrm{Ca}^{2+}\right]_{\mathrm{i}}$ responses of osteocytic networks are significantly dependent on the profiles of fluid flow.
\end{abstract}

(c) 2012 Elsevier Inc. All rights reserved.

\section{Introduction}

Osteocyte networks in bone tissue can sense various mechanical stimuli generated by physical activities and act as an coordinator in the bone remodeling process by regulating both osteoclast and osteoblast activities [1-3]. The heterogeneous deformation across bone tissue induced by mechanical loading creates fluid pressure gradients in the lacunar-canalicular system (LCS), where the osteocytes reside in. This pressure gradient generates fluid flow across the LCS, which can induce shear stresses up to $5 \mathrm{~Pa}$ upon the osteocyte membrane and processes [4-6]. Fluid flow is regarded as an essential mechanical stimulation in the mechanobiology of osteocytes. Due to the versatile nature of human daily activities, the profiles of mechanical loading on bones are complex. Therefore the fluid flow upon osteocytes could be a combination of various patterns, including oscillating fluid flow and unidirectional flow. The oscillating flow is often correlated to cyclic movement of the skeletal system such as walking and running. The unidirectional steady flow can represent a physiological but unusual mechanical stimulus, e.g., a posture

\footnotetext{
* Corresponding author at: Department of Biomedical Engineering, Columbia University, 351 Engineering Terrace, 1210 Amsterdam Avenue, New York, NY 10027, USA. Fax: + 12128548725 .

E-mail address: ed.guo@columbia.edu (X.E. Guo).
}

change of the human body from sitting to standing [7]. Previous studies showed that the mechanically adaptive responses of bone are dominated by "abnormal" strain changes under unusual loading rather than by the numerous cycles of "normal" loadings [8]. Therefore osteocytes respond more actively to new patterns or types of mechanical loadings than to ordinary mechanical stimulation. Osteocytes are known to be able to differentiate the temporal pattern of flow stimulation with distinct biochemical activities to regulate bone remodeling $[1,9,10]$.

Little is known about the mechanobiology effects of different fluid flow profiles on osteocytic networks. To date there has only been one study that compared the responses of osteoblastic cells under the stimuli of steady and oscillatory flows [7]. Significant difference in calcium signaling was revealed in osteoblasts under two flow patterns. The oscillating flow, assumed to be the major stimulation on bone cells, was a much less potent stimulator than the steady flow on osteoblastic cells. We recently found that osteocytic networks, as the dedicated mechanical sensors in bone, are much more sensitive to fluid shear stress than the osteoblasts [11]. The intracellular calcium $\left(\left[\mathrm{Ca}^{2+}\right]_{\mathrm{i}}\right)$ signaling of osteocytes showed significantly different spatiotemporal characteristics with osteoblasts. Unlike the osteoblasts on bone surfaces, osteocyte networks are directly situated inside the LCS. Therefore it is important to understand and compare the responses of osteocytes under different flow patterns, which are 
associated with mechanical loading profiles on bone and further affect the bone remodeling process.

Intracellular calcium $\left[\mathrm{Ca}^{2+}\right]_{i}$ signaling is one of the earliest responses in bone cells under mechanical stimulation that initiates a number of essential downstream signaling pathways, e.g., ATP and $\mathrm{PGE}_{2}$ release, and is typically observed to oscillate dramatically within seconds after mechanical stimulation [4,12-15]. This ubiquitous signaling molecule plays a critical role in a wide variety of physiological processes in bone cells including proliferation, differentiation, and cell responses to mechanical stimuli [16-18]. The calcium wave propagation across neighboring cells acts as an effective mechanism for the cell-cell communication in bone cell networks $[14,19,20]$. The characters of $\left[\mathrm{Ca}^{2+}\right]_{i}$ signaling of bone cells are shown to be dependent on the mechanical loading profiles [21]. We have shown that osteocytes can release multiple spike-like $\left[\mathrm{Ca}^{2+}\right]_{\mathrm{i}}$ peaks under unidirectional fluid flow, up to $17\left[\mathrm{Ca}^{2+}\right]_{\text {i }}$ peaks during a 9-minute flow stimulation. The spatiotemporal properties of the $\left[\mathrm{Ca}^{2+}\right]_{i}$ transients are also found to be dependent on the magnitude of fluid flow. Therefore $\left[\mathrm{Ca}^{2+}\right]_{i}$ oscillations of osteocytes can be employed as a sensitive signaling pathway to represent the cell responses with different external mechanical stimuli.

The fluid flow induced elevation of cytosolic calcium comes mainly from two sources: intracellular stores (e.g., endoplasmic reticulum, ER) and the extracellular environment $[13,22]$. The release of ER calcium store is mainly regulated by the inositol trisphosphate $\left(\mathrm{IP}_{3}\right)$ pathway, which can be initiated by the activation of purinergic receptors on the cell membrane [16,17]. After the cytosolic calcium concentration is elevated to a critical level by intra/extracellular sources, the depleted intracellular calcium stores tend to recover their calcium reservation to original levels and become ready for the next release of calcium [16,23]. When a bone cell is under fluid flow induced shear stress, the activation of gap junction hemichannels (connexin 43 ) induces ATP efflux from the cytosol to the pericellular environment [24]. Extracellular ATP can elicit a significant $\left[\mathrm{Ca}^{2+}\right]_{\mathrm{i}}$ response by binding to the purinergic membrane receptors [25]. Fluid shear stress can also prompt the induction of COX-2 protein and further $\mathrm{PGE}_{2}$ release in osteoblast-like cells [41]. It was previously reported that fluid shear stress can elicit nitric oxide production in osteocytes and osteoblasts accompanied by an increased expression of nitric oxide synthase (NOS) $[26,27]$. Nitric oxide modulates $\left[\mathrm{Ca}^{2+}\right]_{i}$ signaling via a cyclic guanosine monophosphate (cGMP) dependent pathway [28] or nitrosylation of proteins [29]. Moreover, nitric oxide could directly contribute to the $\left[\mathrm{Ca}^{2+}\right]_{\mathrm{i}}$ release via triggering of an influx pathway that is, in part, responsible for the refilling of internal calcium stores [30].

Most studies of bone cell mechanotransduction under oscillatory flow used monolayer osteoblastic cells [7,31-34]. The osteocytes, unlike the osteoblasts residing on the bone surface, are embedded inside the mineralized bone tissue with a regular pattern. The intercellular spacing and the topology of connection dendrites of osteocytes are relatively regular across the tissue. The osteocytes are connected into an extensive network through the gap junctions on processes. Gap junctions are membrane-spanning channels, where each pair of connexons (i.e. hemichannels) forms a cylinder with a pore in the center through which small molecules $(<1 \mathrm{kDa})$ can pass from one cell to another [35]. It is widely accepted that this intercellular connection plays a significant role in coordinating bone cell network activities. Messenger molecules mentioned previously, such as $\mathrm{IP}_{3}$ and calcium, can directly transfer between the neighboring cells through gap junctions and thereby mediate propagation of $\left[\mathrm{Ca}^{2+}\right]_{i}$ signaling in bone cells $[20,36]$. The $\left[\mathrm{Ca}^{2+}\right]_{\mathrm{i}}$ signaling of osteocytes within a controlled cell network connected by gap junctions under different flow stimuli has yet to be obtained experimentally.

In this study, we hypothesize that the $\left[\mathrm{Ca}^{2+}\right]_{\mathrm{i}}$ signaling of osteocytic networks is dependent on the profiles of fluid flow. $\left[\mathrm{Ca}^{2+}\right]_{\mathrm{i}}$ response was employed as the primary outcome variable to compare the physiological responses of in vitro osteocytic networks under steady and oscillatory fluid flows. The roles of several essential $\left[\mathrm{Ca}^{2+}\right]_{\mathrm{i}}$ signaling pathways of osteocytic networks were also investigated and compared under two different flow profiles using pharmacological inhibitors.

\section{Materials and methods}

\section{Chemicals}

Fetal bovine serum (FBS), calf serum (CS), and penicillin/streptomycin $(\mathrm{P} / \mathrm{S})$ were obtained from Hyclone Laboratories Inc. (Logan, UT). Trypsin/ EDTA, octadecanethiol, dimethyl sulfoxide (DMSO), fibronectin, $18 \alpha-$ glycyrrhetinic acid (18 $\alpha-\mathrm{GA})$, suramin, and thapsigargin (TG) were obtained from Sigma-Aldrich Co. (St. Louis, MO). Minimum essential alpha medium ( $\alpha$-MEM), calcium free Dulbecco's modified eagle medium (DMEM), and calcium-free Hank's balanced salt solution (HBSS) were obtained from Invitrogen Corporation (Carlsbad, CA). $\mathrm{N}$-(2-Cyclohexyloxy-4-nitrophenyl) methanesulfonamide (NS-398) and NG-monomethyl-L-arginine (L-NMMA) were from EMD Chemicals Inc. (San Diego, CA).

\section{Cell culture and osteocytic network}

Osteocyte-like MLO-Y4 cells (a gift from Dr. Lynda Bonewald, University of Missouri-Kansas City, Kansas City, MO) were cultured on type I rat tail collagen (BD Biosciences, San Jose, CA, USA) coated Petri-dish in $\alpha$-MEM supplemented with 5\% FBS, 5\% CS and 1\% P/S [37]. Cells were maintained at $37{ }^{\circ} \mathrm{C}$ and $5 \% \mathrm{CO}_{2}$ in a humidified incubator and not allowed to exceed $70-80 \%$ confluence in order to maintain the dendritic characteristic of MLO-Y4 cell line.

Micro-contact printing and self-assembled monolayer (SAM) surface chemistry technologies were employed to construct in vitro osteocytic networks to best simulate the osteocyte network in LCS. The detailed protocol was presented in previous studies [12,38,39]. In brief, a grid mesh cell pattern was printed on a chromium mask, and then the pattern was replicated to a master, made of positive photoresist (Shipley 1818, MicroChem Corp., Newton, MA). Polydimethylsiloxane (PDMS, Sylgard 184, Dow Corning, Midland, MI) stamps were made using the master. To build an osteocytic network on a glass slide, an adhesive SAM (octadecanethiol) was inked onto a gold coated glass slide with the stamp. Ethylene glycol terminated SAM solution ( $\mathrm{HS}-\mathrm{C}_{11}-\mathrm{EG}_{3}$; Prochimia, Sopot, Poland) was then added onto the slide to form a non-adhesive SAM in non-stamped regions, in order to effectively resist cell adhesion. To further improve the cell attachment on the adhesive SAM inked regions, the glass slide was incubated in a $1 \%$ fibronectin solution for $1 \mathrm{~h}$ before cell seeding. Fibronectin can only attach on the adhesive SAM. After the monolayer printing, MLO-Y4 cell suspension medium was dropped onto the slide for cell seeding. Fig. 1A shows a fluorescent image of a typical osteocytic network, in which each cell resides on a round island, which is connected with four neighboring islands through fibronectin coated lines. The cells extend their dendrites through these lines to establish gap junctions with the neighboring cells [38].

\section{$\left[\mathrm{Ca}^{2+}\right]_{i}$ imaging and fluid flow stimulation}

To indicate the fluctuation of $\left[\mathrm{Ca}^{2+}\right]_{i}$ intensity, the osteocytic network was loaded with $10 \mu \mathrm{M}$ Fura-2 AM (Molecular Probes, Eugene, OR) for $45 \mathrm{~min}$ and then rinsed with fresh working medium (phenol-red free $\alpha$-MEM with $2 \%$ FBS and $2 \%$ CS) three times. The glass slide with cells was mounted into a parallel plate flow chamber for laminar fluid flow stimulation tests (Fig. 1B) [13]. The chamber was mounted on an inverted fluorescent microscope (Olympus IX71, Melville, NY), and left undisturbed for $15 \mathrm{~min}$, which has been shown 
A

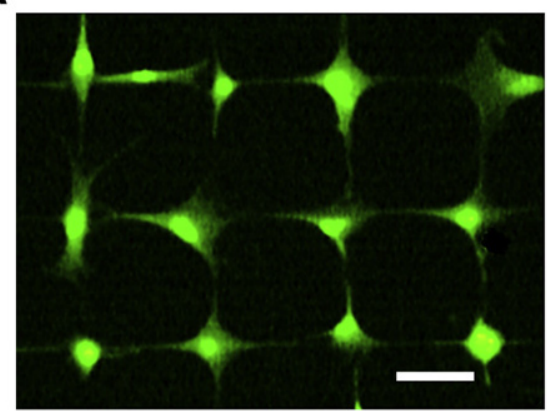

B

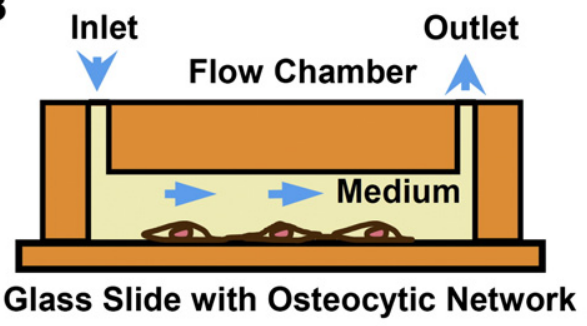

C
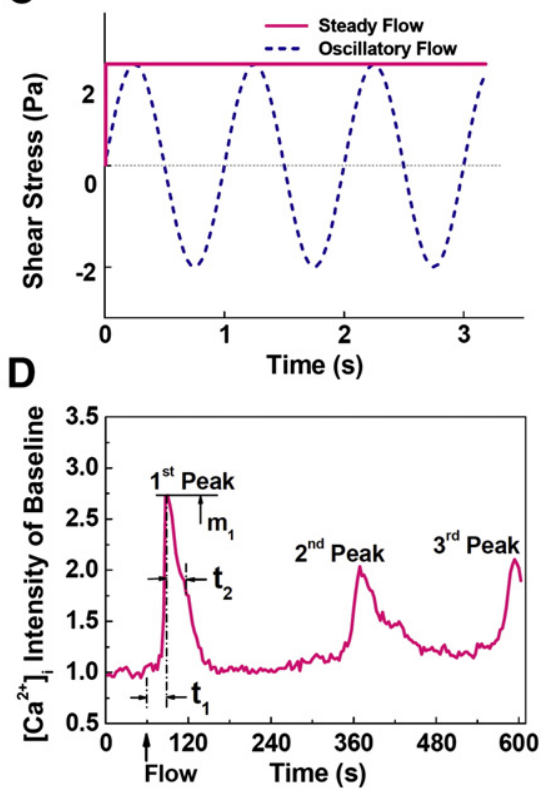

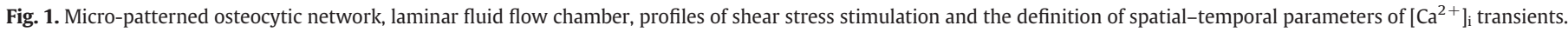

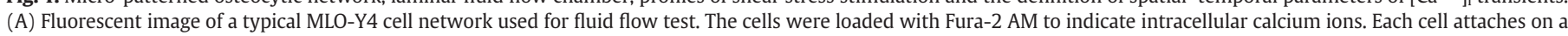

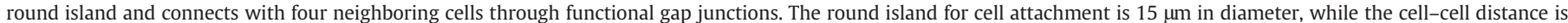

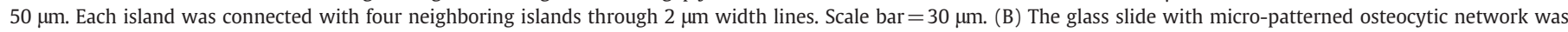

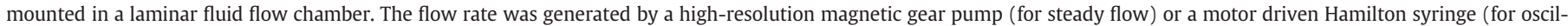

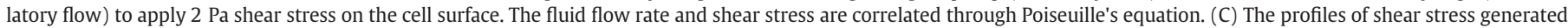

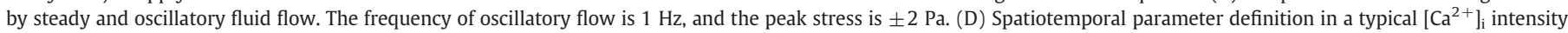

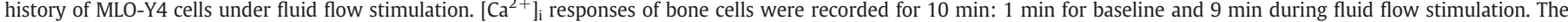

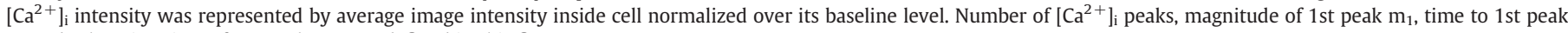
$t_{1}$, and relaxation time of 1 st peak $t_{2}$ were defined in this figure.

to be sufficient for bone cells to recover from mechanical disturbances and to generate repetitive $\left[\mathrm{Ca}^{2+}\right]_{\mathrm{i}}$ response [40]. The fluorescent images of the osteocytic network were recorded by a high-speed CCD camera (ORCA-ER-1394, Hamamatsu Photonics K.K., Hamamatsu City, Japan) for a 10-minute period, $1 \mathrm{~min}$ for baseline and 9 min after the onset of fluid flow. Fura-2 $340 \mathrm{~nm} / 380 \mathrm{~nm}$ ratio images were used to obtain the fluctuation history of $\left[\mathrm{Ca}^{2+}\right]_{i}$ by measuring the average image intensity of each cell using MetaMorph and MetaFluor Imaging Software 7.0 (Molecular Devices, Downingtown, PA). The intensity of $\left[\mathrm{Ca}^{2+}\right]_{\mathrm{i}}$ was normalized by the baseline of each cell.

To generate steady fluid flow in the laminar flow chamber, a magnetic gear pump was connected to the chamber with rigid walled tubing to push the fresh working medium through at a desired constant flow rate. The oscillatory flow was driven by a Hamilton glass syringe which was connected to a crank-rocker mechanism. The rocker was driven by a DC motor rotating at $1 \mathrm{~Hz}$ which results in a sinusoidal oscillatory laminar flow in the chamber [7]. The shear stress of the steady flow or peak shear stress of oscillatory flow on cell surfaces was controlled at $2 \mathrm{~Pa}$. The profiles of oscillatory and steady flow were illustrated in Fig. 1C.

\section{$\left[\mathrm{Ca}^{2+}\right]_{i}$ signaling related pathways}

To identify the potential cellular mechanisms activated by different fluid flow profiles, the osteocytic networks were separated into eight groups for each flow pattern. With exception to the untreated and vehicle (DMSO) control groups, the fluid flow experiments were performed with the presence of six specific pathway inhibitors. Each inhibitor can block a major $\left[\mathrm{Ca}^{2+}\right]_{i}$ signaling related pathway in bone cells (Fig. 2). (1) Extracellular calcium depletion: calcium-free DMEM and calcium-free HBSS were used to replace the regular medium in flow tests. (2) ER calcium store depletion: cell networks were incubated in $1 \mu \mathrm{M}$ thapsigargin medium to deplete the calcium in the ER store for a half hour before flow tests [25]. (3) $P G E_{2}$ blocking: cell networks were treated with $10 \mu \mathrm{M}$ NS-398 for $24 \mathrm{~h}$ before and during the flow test, which

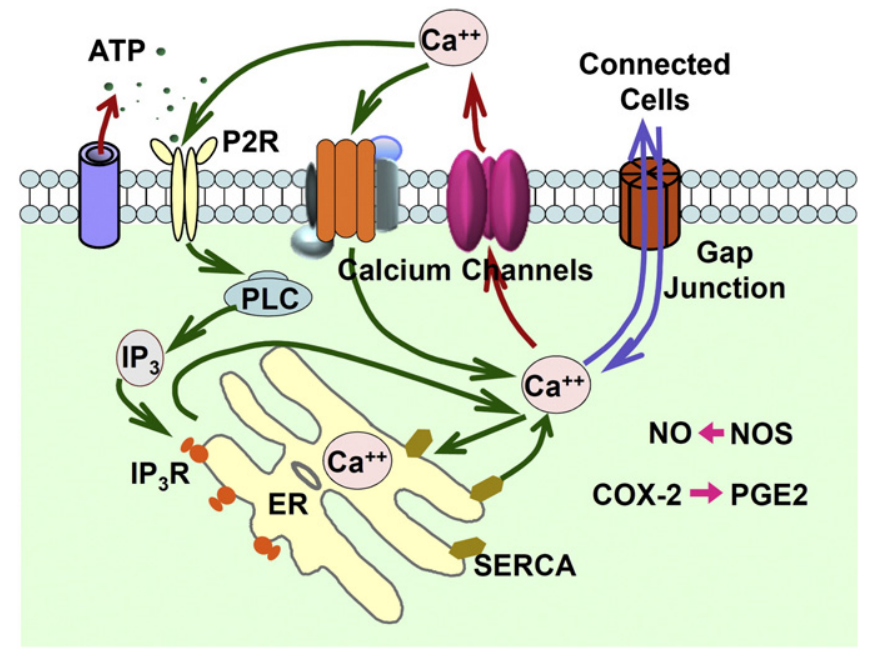

Fig. 2. A schematic of calcium signaling pathways in osteocytes investigated in present study. The increase of $\mathrm{Ca}^{2+}$ intensity in cytoplasm has two major sources, the extracellular $\mathrm{Ca}^{2+}$ in medium and intracellular calcium store in ER. Ion channels, such as voltage gated calcium channels, ligand gated ion channels and stretch-activated ion channels can transfer $\mathrm{Ca}^{2+}$ between intra- and extracellular environments. The calcium in ER store can be released by activation of $\mathrm{IP}_{3}$ sensitive channels. $\left[\mathrm{Ca}^{2+}\right]_{\mathrm{i}}$ signaling in bone cells can induce ATP release through hemi-channels on membrane. ATP can further activate the purinergic receptors which are correlated with PLC and $\mathrm{IP}_{3}$ pathway. Gap junction between neighboring cells provides a physical channel for small molecules (e.g., $\mathrm{IP}_{3}$ and $\mathrm{Ca}^{2+}$ ) to diffuse between two connected cells. As two of the essential signaling pathways involved in bone mechanotransduction, $\mathrm{PGE}_{2}$ and NO pathways were investigated to identify their correlations with mechanical loading induced $\left[\mathrm{Ca}^{2+}\right]_{\mathrm{i}}$ responses. 
Table 1

Number of analyzed cells in different experimental groups.

\begin{tabular}{lllrlllll}
\hline Pathway & Untreated & NO & ATP & $\mathrm{Ca}^{2+}$ free & Vehicle & PGE $_{2}$ & GJ & ER store \\
\hline Oscillatory & 412 & 394 & 225 & 152 & 396 & 398 & 323 & 134 \\
Steady & 441 & 131 & 95 & 66 & 151 & 139 & 125 & 111 \\
\hline
\end{tabular}

can selectively inhibit the COX-2 enzyme activity and further block the $\mathrm{PGE}_{2}$ release [41]. (4) NO blocking: $100 \mu \mathrm{M}$ L-NMMA was introduced into the cell culture medium one day before seeding the cells on slides and continuously presented in medium afterwards. L-NMMA inhibits the production of nitric oxide via competitively inhibiting all three isoforms of nitric oxide synthase (NOS) [42]. (5) Gap junction blocking: $75 \mu \mathrm{M} 18 \alpha-\mathrm{GA}$, a reversible gap junction blocker which binds to membrane proteins and causes disassembly of gap junction plaques [43], was supplied in fluid flow medium to investigate the roles of gap junction in calcium wave propagation [36]. (6) Extracellular ATP pathway blocking: $100 \mu \mathrm{M}$ suramin, a general P2 purinergic receptor blocker, was applied to the cell networks $30 \mathrm{~min}$ prior to fluid flow stimulation [44]. The concentrations of above agents were selected according to the relevant literature where they have been demonstrated to be effective on bone cells. We have used both $18 \alpha-$ GA and NS-398 in bone explant studies for long term (up to 4 weeks) and have not observed osteocyte cell death [53]. Each individual group included more than three slides with patterned cell networks. The numbers of total analyzed cells in each group were summarized in Table 1.

\section{Data analysis and statistics}

A cell was defined as responsive to the fluid flow stimulation if it released a calcium spike with a magnitude four times higher than its fluctuations during the period of baseline measurement [45]. Responsive percentage of cells in each group was defined as the number of responsive cells divided by the total number of analyzed cells in the group. To quantitatively analyze the spatial-temporal characteristics of the $\left[\mathrm{Ca}^{2+}\right]_{i}$ transients, a set of parameters was defined as shown in Fig. 1D. The number of $\left[\mathrm{Ca}^{2+}\right]_{i}$ peaks during the stimulation period, the magnitude of the $1 \mathrm{st}\left[\mathrm{Ca}^{2+}\right]_{\mathrm{i}}$ peak, and the time to reach the first peak after the onset of fluid flow were measured and compared between different groups. Student t-tests were used to determine significant difference of spatiotemporal parameters between oscillatory and steady flows. One-way analysis of variance (ANOVA) with Bonferroni's post hoc analysis was performed to determine statistical differences between mean values of different pathway inhibited groups. L-NMMA, suramin and $\mathrm{Ca}^{2+}$ free medium treated groups were compared with the untreated group. Since NS398, 18 $\alpha$-GA and thapsigargin were originally dissolved in DMSO, the results from these three groups were compared with those of DMSO vehicle control group. All data reported are mean \pm standard deviation of the values of all responsive cells. Statistical significance was defined as $p<0.05$.

\section{Results}

A set of typical $\left[\mathrm{Ca}^{2+}\right]_{\mathrm{i}}$ transients of MLO-Y4 cells under oscillatory and steady fluid flow stimulation is shown in Fig. 3. Both flow patterns induced prominent $\left[\mathrm{Ca}^{2+}\right]_{\mathrm{i}}$ oscillations in MLO-Y4 cells. Under oscillating flow stimulation, the cell released a $\left[\mathrm{Ca}^{2+}\right]_{i}$ peak at the onset of flow and a few weaker peaks afterwards with reduced magnitudes. Under steady flow stimulation, MLO-Y4 cells tended to release repetitive and spike-like $\left[\mathrm{Ca}^{2+}\right]_{i}$ peaks with no attenuation in magnitude. A single cell can release up to $17\left[\mathrm{Ca}^{2+}\right]_{\mathrm{i}}$ peaks in $9 \mathrm{~min}$ under steady flow, but at most $6\left[\mathrm{Ca}^{2+}\right]_{i}$ peaks under oscillating flow.

The responsive percentages of MLO-Y4 cells under oscillating (96\%) and steady (95\%) fluid flow had no significant difference. Less

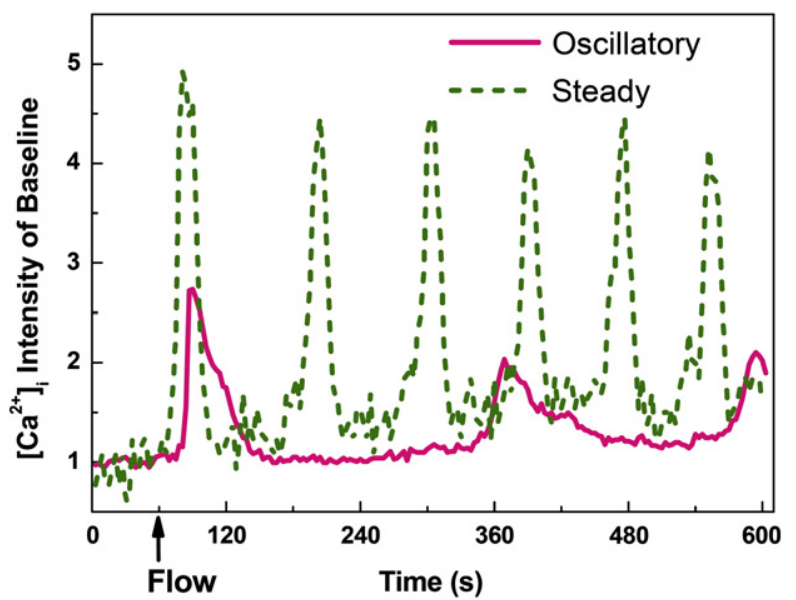

Fig. 3. A set of typical $\left[\mathrm{Ca}^{2+}\right]_{i}$ responses of MLO-Y4 cells under steady and oscillatory fluid flow stimulations. The flow starts at the 60th second and lasts for 9 min in both tests.

than $5 \%$ of cells failed to respond to 2 Pa shear stress stimulation (Fig. 4A). The number of multiple $\left[\mathrm{Ca}^{2+}\right]_{i}$ peaks was much higher under steady flow $(4.3 \pm 2.8)$ than under oscillating flow $(2.4 \pm 1.6)$ (Fig. 4B). 58\% MLO-Y4 cells can release three or more $\left[\mathrm{Ca}^{2+}\right]_{i}$ peaks under 9-minute steady flow stimulation. The same percentage decreased to $21 \%$ under oscillatory flow stimulation. The average magnitude of the first $\left[\mathrm{Ca}^{2+}\right]_{i}$ peak under steady flow $(3.3 \pm 2.6)$ was significantly higher than that under oscillating flow (2.5 \pm 1.5$)$, and it took the cells significantly shorter time to reach the first peak under steady flow $(21 \pm 11 \mathrm{~s} v$ s. $37 \pm 29 \mathrm{~s}$ under oscillatory flow $)$.

The responsive percentages of all sixteen pharmacological treated groups were summarized in Fig. 5. Under both flow patterns, MLO-Y4 cells showed no $\left[\mathrm{Ca}^{2+}\right]_{i}$ responses when calcium free medium were used. Under steady flow stimulation, the responsive percentages
A

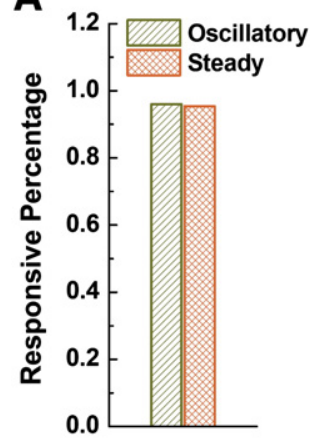

C

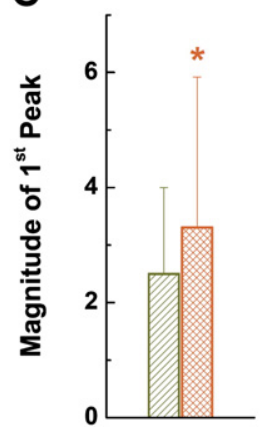

B

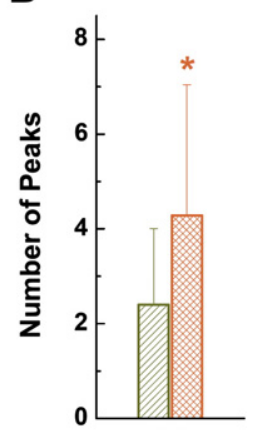

D

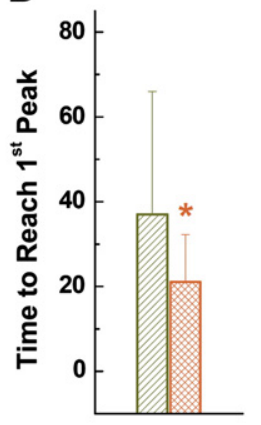

Fig. 4. Comparison of spatiotemporal characteristics of the first $\left[\mathrm{Ca}^{2+}\right]_{i}$ peaks in MLO-Y4 cells under oscillatory and steady fluid flow: (A) percentage of responsive cells, (B) average number of $\left[\mathrm{Ca}^{2+}\right]_{i}$ peaks, (C) magnitude of the $1 \mathrm{st}\left[\mathrm{Ca}^{2+}\right]_{i}$ peaks, and (D) time from onset of fluid flow to reach the 1 st $\left[\mathrm{Ca}^{2+}\right]_{\text {i peak }}\left({ }^{*}: p<0.05\right)$. 


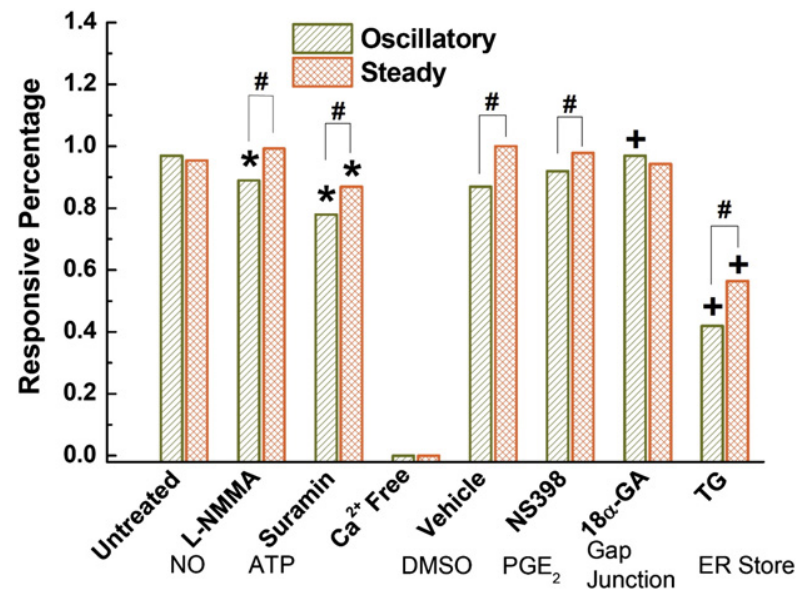

Fig. 5. Percentage of responsive cells under fluid flow with different pathways blocked in MLO-Y4 cells. The blocked pathways are listed below the corresponding pharmacological chemicals employed. L-NMMA, Suramin and $\mathrm{Ca}^{2+}$ free medium treated groups were compared with the untreated group. NS398, 18 $\alpha$-GA and thapsigargin treated groups were compared with the DMSO vehicle control group. The cells treated with $\mathrm{Ca}^{2+}$ free medium had no responses to fluid flow stimulation. * means significant difference with corresponding untreated group, and + with vehicle control group. \# represents significant difference between the two connected groups, $p<0.05$.

were above $85 \%$ in all groups except the ER calcium store depleted group (57\%). The ER depleted group (57\%) and ATP pathway blocked group (87\%) showed significantly lower responsive percentages than the corresponding control groups under steady flow. Under oscillatory flow stimulation, the ER depleted group (42\%), NO (89\%), and ATP (78\%) interrupted groups showed significantly lower responsive percentages than corresponding controls, while the $18 \alpha$-GA treatment increased the responsive percentage ( $97 \%$ vs $87 \%$ in vehicle control group). In the NO, ATP, $\mathrm{PGE}_{2}$, and ER calcium store inhibited groups, the responsive percentages of cells are significantly lower under the oscillating flow than the steady flow, while other pharmacological treatment groups showed no significant difference between two fluid flow patterns.

Fig. 6 shows the number of $\left[\mathrm{Ca}^{2+}\right]_{i}$ peaks in all groups. In the NO pathway and ER calcium store interrupted groups, steady flow stimulated cells showed significantly more peaks than corresponding groups under oscillatory flow. The number of $\left[\mathrm{Ca}^{2+}\right]_{i}$ peaks in the two ATP pathway inhibited groups decreased close to 1 and had no

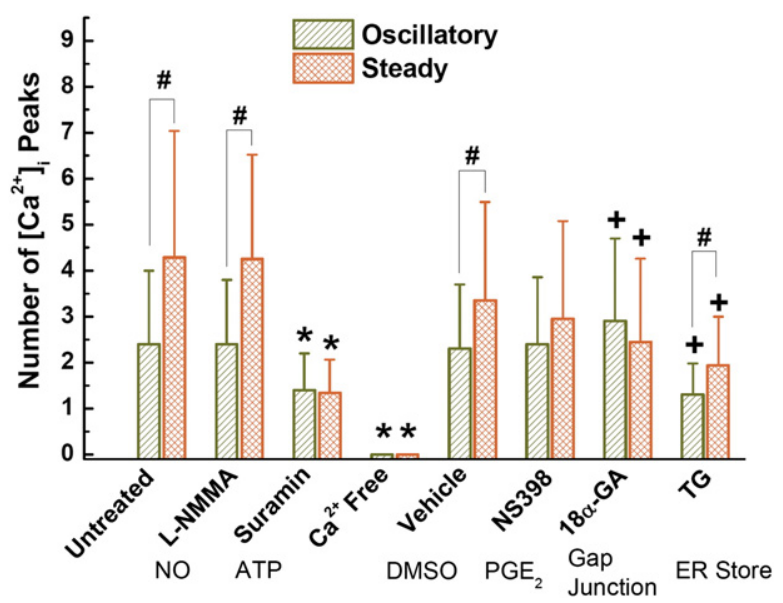

Fig. 6. The average number of responsive $\left[\mathrm{Ca}^{2+}\right]_{i}$ peaks in MLO-Y4 cells treated with pharmacological inhibitors. The affected pathways are listed below the corresponding chemicals. * means significant difference with corresponding untreated group, and + with vehicle control group. \# represents significant difference between the two connected groups, $p<0.05$.

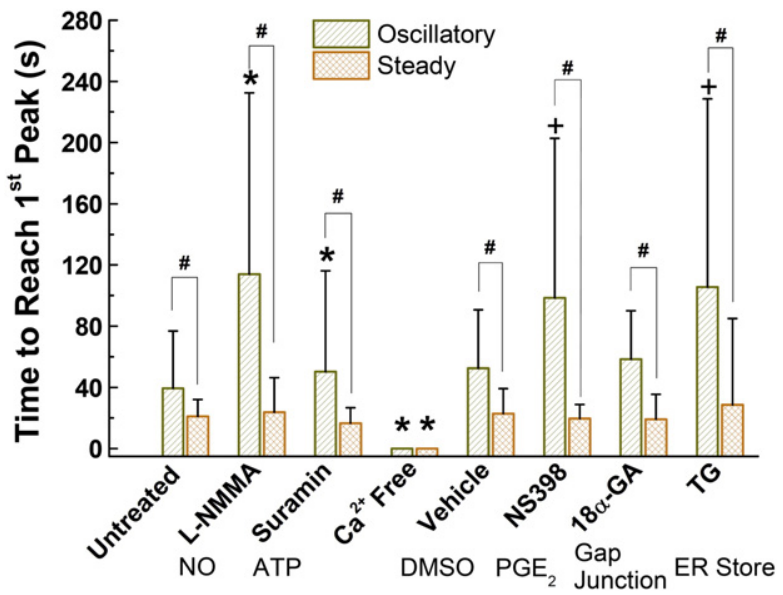

Fig. 7. The time to reach $1 \mathrm{st}\left[\mathrm{Ca}^{2+}\right]_{\mathrm{i}}$ peak in MLO-Y4 cells after the start of fluid flow stimulation. The inhibited pathways are listed below the chemicals employed. * means significant difference with corresponding untreated group, and + with vehicle control group. \# represents significant difference between the oscillatory and steady flow groups, $p<0.05$.

difference under two flow profiles. The ER calcium store depleted groups under both flow profiles showed the average number of $\left[\mathrm{Ca}^{2+}\right]_{i}$ peaks less than two, significantly lower than corresponding vehicle control groups. When the gap junctions were blocked by $18 \alpha-G A$, the number of $\left[\mathrm{Ca}^{2+}\right]_{i}$ peaks under oscillatory flow was higher than the vehicle control group, which is opposite to the result under steady flow. Disruption of $\mathrm{NO}$ and $\mathrm{PGE}_{2}$ pathways had no significant influence on the number of $\left[\mathrm{Ca}^{2+}\right]_{i}$ peaks compared with corresponding control groups. MLO-Y4 cells took significantly longer time to reach the first $\left[\mathrm{Ca}^{2+}\right]_{i}$ peak under oscillating flow than under steady flow in all groups (Fig. 7). Interestingly, this timing gap is even broadened when the cells were treated with pathway inhibitors. In most groups under steady flow, except the calcium free medium group, chemical treatment showed no significant effect on the time to reach the first $\left[\mathrm{Ca}^{2+}\right]_{i}$ peaks. In contrast, when MLO-Y4 cells were stimulated with oscillatory flow, the time to reach the first peak was significantly increased in ER store depleted group, ATP, NO and PGE $_{2}$ pathway blocked groups when compared to the untreated or vehicle groups. The time was lengthened three times in NO blocked group, and twice for ER store depleted group. Interestingly, no significant difference was detected in the response speed between the vehicle control and $18 \alpha-G A$ treated groups under oscillatory flow.

\section{Discussion}

In this study, the calcium signaling of osteocytic networks was investigated and compared under the stimulation of steady or oscillatory fluid flow. The results clearly demonstrated that the oscillatory flow is significantly less potent than the steady flow to osteocytes. Osteocytes tend to release more frequent $\left[\mathrm{Ca}^{2+}\right]_{i}$ peaks with higher magnitudes under the stimulation of steady fluid flow than under the oscillatory flow. Previous studies on monolayer osteoblastic cells also showed that in vitro oscillating flow is far less stimulatory than the unidirectional flow [7]. The responsive percentage, but not the response amplitude, of osteoblasts is dependent on the flow profiles. Thus an "all or nothing" $\left[\mathrm{Ca}^{2+}\right]_{\mathrm{i}}$ response character was proposed for osteoblastic cells under fluid flow stimuli [7]. In the present study, however, the responsive percentages of osteocytes show no significant differences between the two flow patterns, but significant differences in the spatiotemporal characters were observed in the $\left[\mathrm{Ca}^{2+}\right]_{\mathrm{i}}$ transients, i.e., more frequent and stronger $\left[\mathrm{Ca}^{2+}\right]_{\mathrm{i}}$ peaks under steady flow than under oscillatory flow. In our previous studies on the calcium signaling of osteocytes under fluid shear stress ranging 
from 0.5 to $4 \mathrm{~Pa}$, it was also found that the spatiotemporal parameters, but not responsive percentages of osteocytes, are correlated with the strength of fluid shear stress [11]. Therefore the information regarding the profiles of fluid flow is represented by the spatiotemporal characters of $\left[\mathrm{Ca}^{2+}\right]_{i}$ transients rather than by the responsive percentage of osteocytes. This finding is opposite to that revealed in osteoblasts [7], which further implies that the osteocytes and osteoblasts may incorporate different $\left[\mathrm{Ca}^{2+}\right]_{\mathrm{i}}$ signaling mechanisms under similar mechanical stimuli. Our previous studies also confirmed that the osteocytic and osteoblastic networks had dramatically different $\left[\mathrm{Ca}^{2+}\right]_{\mathrm{i}}$ responses under the same steady fluid flow stimulation. The $\left[\mathrm{Ca}^{2+}\right]_{\mathrm{i}}$ transients of osteocytes are much more dynamic than those of osteoblasts. It has been shown that the expression of T-type voltage gated calcium channels in osteocytes may play an essential role in the spike-like $\left[\mathrm{Ca}^{2+}\right]_{\mathrm{i}}$ responses of MLO-Y4 cells under mechanical stimulation $[11,46,47]$.

The exact mechanism of fluid shear stress induced $\left[\mathrm{Ca}^{2+}\right]_{i}$ signaling in bone cells remains elusive, but several essential pathways in bone remodeling process have been proven to interact with $\left[\mathrm{Ca}^{2+}\right]_{\mathrm{i}}$ responses in osteoblasts $[15,20,31,32,48]$. In this study, we found that the fluid flow induced $\left[\mathrm{Ca}^{2+}\right]_{\mathrm{i}}$ responses in osteocytes involve the gap junction, $\mathrm{PGE}_{2}$, NO and ATP related pathways. Purinergic receptors on cell membrane are especially critical for the release of multiple $\left[\mathrm{Ca}^{2+}\right]_{i}$ peaks in MLO-Y4 cells under both steady and oscillatory flows. The results also proved that the $\left[\mathrm{Ca}^{2+}\right]_{\mathrm{i}}$ responses of osteocytes rely on two major calcium sources, the extracellular calcium in medium and intracellular calcium stored in ER, while the release of ER store has to be initiated by the influx of extracellular calcium. Osteocytic networks stopped responding to fluid flow in calcium-free medium, and the depletion of calcium in

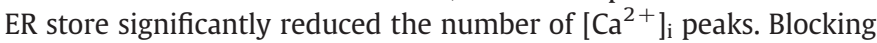
these pathways showed similar effects on the number of $\left[\mathrm{Ca}^{2+}\right]_{\mathrm{i}}$ peaks under both oscillating and unidirectional flow patterns. However, the time to reach the first peak was significantly increased in most chemical-treated groups under oscillating flow stimulation, but not under steady flow. This indicates that the $\left[\mathrm{Ca}^{2+}\right]_{i}$ transients in osteocytes are more readily affected by pharmacological treatment under oscillating fluid flow, the assumed "normal" stimulation on osteocytes.

Compared with the interruption of ATP pathway, intra- and extracellular calcium sources, the blocking of $\mathrm{NO}$ and $\mathrm{PGE}_{2}$ release showed less significant effects on the flow induced $\left[\mathrm{Ca}^{2+}\right]_{i}$ signaling in MLO-Y4 cells. Since the upregulation of NO release is another early response of osteocytes under fluid flow stimulation, which occurs in a few minutes $[49,50]$, it is highly possible that NO release and $\left[\mathrm{Ca}^{2+}\right]_{\mathrm{i}}$ signaling can interfere with each other. The production of NO in human bone cells is mainly regulated by the endothelial nitric oxide synthase [51]. According to the time reaching the $1 \mathrm{st}\left[\mathrm{Ca}^{2+}\right]_{\mathrm{i}}$ peaks demonstrated in the present study $(20 \mathrm{~s}$ in the control group), the flow induced $\left[\mathrm{Ca}^{2+}\right]_{\mathrm{i}}$ signaling in osteocytes is even faster than the NO release. Therefore it is unlikely the $\left[\mathrm{Ca}^{2+}\right]_{i}$ signaling is a downstream activity of NO release in flow-stimulated osteocytes. Our previous studies on osteoblasts also showed that activation of NO release has no essential influence on the flow induced $\left[\mathrm{Ca}^{2+}\right]_{i}$ signaling. The $\mathrm{PGE}_{2}$ release under fluid flow starts even later than NO [49], and the treatment of L-NMMA prevented both $\mathrm{NO}$ and $\mathrm{PGE}_{2}$ release in chicken osteocytes, suggesting that the upregulation of $\mathrm{PGE}_{2}$ is dependent on the NO pathway. Thus it is not a surprise that the inhibition of $\mathrm{PGE}_{2}$ release did not reduce the calcium responsive percentage of osteocytes in the present study.

Most pharmacological treatments in this study had negative effects on the $\left[\mathrm{Ca}^{2+}\right]_{i}$ responses of MLO-Y4 cells. Interestingly, the treatment with $18 \alpha-G A$ increased the responsive percentage and number of peaks in cells under oscillating flow, but not under steady flow, and the speed of calcium response has no significant difference with the vehicle control group. The $18 \alpha-$ GA has been widely used in bone cell research to block the intercellular gap junctions. A number of studies from our group and other groups have proven the effectiveness of this chemical in blocking gap junction and its effect on calcium signaling [11,12,14,15,19,24,36,43,52,53]. Our previous studies using a bone explant model also showed that $18 \alpha$-GA treatment attenuated the effects of mechanical loading in new bone formation while having minimal toxic effects on osteocyte health in a 4-week long culture [53]. It is interesting that the treatment of $18 \alpha-$ GA on MLO-Y4 cells boosts the calcium responses under oscillatory fluid flow. Identifying the exact mechanisms responsible for this unexpected result may require extensive studies, which is beyond the scope of this present work. However, this result from $18 \alpha$-GA treatment revealed a critical difference between the stimulative effects of steady and oscillatory flow in osteocyte mechanotransduction. Finally, it is important to note the limitations of the usage of chemical inhibitors. Each pharmacological chemical may have complex effects on the cells besides its major functions. Therefore, a thorough understanding of the mechanisms of these pathways in calcium signaling may require comprehensive studies using a combination of various techniques.

Osteocytic networks are regarded as the major mechanical sensor in bone modeling and remodeling processes. A number of studies showed that the bone is more sensitive to the change of mechanical environments rather than the magnitude or duration of loading [54]. Partitioning exercise into multiple sessions is much more effective for "training" bone to be stronger [55]. Five jumps per day can significantly increase the bone volume and fracture stiffness in rats [56]. However, little information is available about the correlation between the loading profiles and osteocyte behaviors. During cyclic movement of the human body, such as walking and running, a normal oscillatory fluid flow is expected in the LCS in bone. However, a posture change, such as from sitting to standing, may induce a constant, nonhomogeneous strain field in the bone. Due to the low permeability of LCS and the dense glycocalyx surrounding the osteocyte processes, this pressure gradient in the LCS may generate a minutes-long, steady fluid flow on osteocytes. Our recent study demonstrated a high viscoelasticity in osteocyte cytoskeletal networks under fluid flow loading [57]. The cell deformation slowly "creeps" to the equilibrium state under the constant push from a unidirectional flow. This process could take minutes under $1 \mathrm{~Pa}$ shear stress. Therefore the stress and strain developed in the cell body and processes under steady flow could be significantly higher than those under oscillatory flow. The difference in deformation amplitudes of the cell membrane and cell body may contribute to the differences in $\left[\mathrm{Ca}^{2+}\right]_{i}$ signaling revealed in the present study. Previous research using MC3T3-E1 cells also found that the stretch-activated membrane channel, blocked using gadolinium chloride, is not important for cell response to oscillatory fluid flow [32], but calcium responses were inhibited by blocking this channel under steady flow [13,22]. Furthermore, mechanotransduction responses in MC3T3-E1 cells were shown to be induced by a mechanism that involves the reorganization of the actin cytoskeleton under unidirectional steady fluid flow [58], while exposure to oscillatory fluid flow failed to result in the development of F-actin stress fibers in osteoblastic cells [34]. Combining all of these factors with the results in this study, it is clear that the different stimulation effects of steady and oscillatory flows are related to the distinct strain fields developed in the cytoskeleton under two flow patterns. Another significant difference between steady and oscillatory flows is the effective volume of medium which the cells are exposed to. The cells are exposed to much more medium under the steady flow than the oscillatory flow. Therefore, essential biochemical factors for $\left[\mathrm{Ca}^{2+}\right]_{i}$ signaling within the medium would be depleted more rapidly under steady flow, and the messengers secreted from cells, such as ATP, would accumulate faster and higher within the small volume of oscillating medium. Identifying the existence and mechanisms of these factors could be a challenging yet important direction for future studies on this topic. 


\section{Conclusion}

In summary, this study proved that fluid flow can induce robust intracellular calcium responses in osteocytic networks. The responsive percentage of osteocytes is not dependent on the flow patterns, but the spatiotemporal characteristics of calcium transients vary significantly under steady and oscillatory flows. Osteocytes can release more intracellular calcium peaks with higher magnitudes under steady flow than under oscillatory flow, i.e., steady flow is more stimulative to osteocytes than oscillatory flow. Experiments using pharmacological inhibitors demonstrated that extracellular calcium source in medium, intracellular calcium store in ER, and purinergic receptors on cell membrane are essential for calcium signaling of osteocytes under fluid flow stimulation.

\section{Funding sources} (XEG).

NIH grants R21 AR052417, R01 AR052461, and RC1 AR058453

\section{Disclosures/conflicts of interest}

The authors have nothing to disclose, and have no conflicts of interest.

\section{Acknowledgments}

We thank Dr. L. Bonewald for her generous gift of MLO-Y4 cells.

\section{References}

[1] Bonewald LF. The amazing osteocyte. J Bone Miner Res 2011;26:229-38.

[2] Piekarski K, Munro M. Transport mechanism operating between blood-supply and osteocytes in long bones. Nature 1977;269:80-2.

[3] Tatsumi S, Ishii K, Amizuka N, Li M, Kobayashi T, Kohno K, et al. Targeted ablation of osteocytes induces osteoporosis with defective mechanotransduction. Cell Metab 2007:5:464-75.

[4] Riddle RC, Donahue HJ. From streaming-potentials to shear stress: 25 years of bone cell mechanotransduction. J Orthop Res 2009;27:143-9.

[5] Weinbaum S, Cowin SC, Zeng Y. A model for the excitation of osteocytes by mechanical loading-induced bone fluid shear stresses. J Biomech 1994;27:339-60.

[6] Price C, Li W, Novotny JE, Wang LY. An in-situ fluorescence-based optical extensometry system for imaging mechanically loaded bone. J Orthop Res 2010;28:805-11.

[7] Jacobs CR, Yellowley CE, Davis BR, Zhou Z, Cimbala JM, Donahue HJ. Differential effect of steady versus oscillating flow on bone cells. J Biomech 1998;31:969-76.

[8] Turner CH, Robling AG, Duncan RL, Burr DB. Do bone cells behave like a neuronal network? Calcif Tissue Int 2002;70:435-42.

[9] Klein-Nulend J, van der Plas A, Semeins CM, Ajubi NE, Frangos JA, Nijweide PJ, et al. Sensitivity of osteocytes to biomechanical stress in vitro. FASEB J 1995;9: 441-5.

[10] Kamel MA, Picconi JL, Lara-Castillo N, Johnson ML. Activation of $\beta$-catenin signaling in MLO-Y4 osteocytic cells versus 2 t3 osteoblastic cells by fluid flow shear stress and $\mathrm{PGE}_{2}$ : Implications for the study of mechanosensation in bone. Bone 2010;47:872-81.

[11] Lu XL, Huo B, Chiang V, Guo XE. Osteocytic network is more responsive in calcium signaling than osteoblastic network under fluid flow. J Bone Miner Res 2012;27: 563-74.

[12] Huo B, Lu XL, Hung CT, Costa KD, Xu QB, Whitesides GM, et al. Fluid flow induced calcium response in bone cell network. Cell Mol Bioeng 2008;1:58-66.

[13] Hung CT, Allen FD, Pollack SR, Brighton CT. Intracellular $\mathrm{Ca}^{2+}$ stores and extracellular $\mathrm{Ca}^{2+}$ are required in the real-time $\mathrm{Ca}^{2+}$ response of bone cells experiencing fluid flow. J Biomech 1996;29:1411-7.

[14] Huo B, Lu XL, Costa KD, Xu QB, Guo XE. An ATP-dependent mechanism mediates intercellular calcium signaling in bone cell network under single cell nanoindentation. Cell Calcium 2010;47:234-41.

[15] Jorgensen NR, Geist ST, Civitelli R, Steinberg TH. ATP- and gap junction-dependent intercellular calcium signaling in osteoblastic cells. J Cell Biol 1997;139:497-506.

[16] Berridge MJ, Lipp P, Bootman MD. The versatility and universality of calcium signalling. Nat Rev Mol Cell Biol 2000;1:11-21.

[17] Iqbal J, Zaidi M. Molecular regulation of mechanotransduction. Biochem Biophys Res Commun 2005;328:751-5.

[18] Zayzafoon M. Calcium/calmodulin signaling controls osteoblast growth and differentiation. J Cell Biochem 2006;97:56-70.

[19] Huo B, Lu XL, Guo XE. Intercellular calcium wave propagation in linear and circuit-like bone cell networks. Philos Trans R Soc A 2010;368:617-33.
[20] Jorgensen NR, Henriksen Z, Brot C, Eriksen EF, Sorensen OH, Civitelli R, et al Human osteoblastic cells propagate intercellular calcium signals by two different mechanisms. J Bone Miner Res 2000;15:1024-32.

[21] Donahue SW, Jacobs CR, Donahue HJ. Flow-induced calcium oscillations in rat osteoblasts are age, loading frequency, and shear stress dependent. Am J Physiol Cell Physiol 2001;281:C1635-41.

[22] Chen NX, Ryder KD, Pavalko FM, Turner CH, Burr DB, Qiu JY, et al. $\mathrm{Ca}^{2+}$ regulates fluid shear-induced cytoskeletal reorganization and gene expression in osteoblasts. Am J Physiol Cell Physiol 2000;278:C989-97.

[23] Mogami H, Tepikin AV, Petersen OH. Termination of cytosolic $\mathrm{Ca}^{2+}$ signals: $\mathrm{Ca}^{2+}$ reuptake into intracellular stores is regulated by the free $\mathrm{Ca}^{2+}$ concentration in the store lumen. EMBO J 1998;17:435-42.

[24] Genetos DC, Kephart CJ, Zhang Y, Yellowley CE, Donahue HJ. Oscillating fluid flow activation of gap junction hemichannels induces ATP release from MLO-Y4 osteocytes. J Cell Physiol 2007;212:207-14.

[25] Hung CT, Allen FD, Mansfield KD, Shapiro IM. Extracellular ATP modulates $\left[\mathrm{Ca}^{2+}\right]_{\mathrm{i}}$ in retinoic acid-treated embryonic chondrocytes. Am J Physiol 1997;272:C1611-7.

[26] Zaman G, Pitsillides AA, Rawlinson SC, Suswillo RF, Mosley JR, Cheng MZ, et al. Mechanical strain stimulates nitric oxide production by rapid activation of endothelial nitric oxide synthase in osteocytes. J Bone Miner Res 1999;14: 1123-31.

[27] McGarry JG, Klein-Nulend J, Prendergast PJ. The effect of cytoskeletal disruption on pulsatile fluid flow-induced nitric oxide and prostaglandin $\mathrm{E}_{2}$ release in osteocytes and osteoblasts. Biochem Biophys Res Commun 2005;330: 341-8.

[28] Looms DK, Tritsaris K, Nauntofte B, Dissing S. Nitric oxide and cGMP activate $\mathrm{Ca}^{2+}$-release processes in rat parotid acinar cells. Biochem J 2001;355: 87-95.

[29] Volk T, Mading K, Hensel M, Kox WJ. Nitric oxide induces transient $\mathrm{Ca}^{2+}$ changes in endothelial cells independent of cGMP. J Cell Physiol 1997;172:296-305.

[30] Li N, Sul JY, Haydon PG. A calcium-induced calcium influx factor, nitric oxide, modulates the refilling of calcium stores in astrocytes. J Neurosci 2003;23: 10302-10.

[31] You J, Jacobs CR, Steinberg TH, Donahue HJ. P2Y purinoceptors are responsible for oscillatory fluid flow-induced intracellular calcium mobilization in osteoblastic cells. J Biol Chem 2002;277:48724-9.

[32] You J, Reilly GC, Zhen XC, Yellowley CE, Chen Q, Donahue HJ, et al. Osteopontin gene regulation by oscillatory fluid flow via intracellular calcium mobilization and activation of mitogen-activated protein kinase in MC3T3-E1 osteoblasts. J Biol Chem 2001;276:13365-71.

[33] You J, Yellowley CE, Donahue HJ, Zhang Y, Chen Q, Jacobs CR. Substrate deformation levels associated with routine physical activity are less stimulatory to bone cells relative to loading-induced oscillatory fluid flow. J Biomech Eng 2000;122: 387-93.

[34] Malone AM, Batra NN, Shivaram G, Kwon RY, You L, Kim CH, et al. The role of actin cytoskeleton in oscillatory fluid flow-induced signaling in MC3T3-E1 osteoblasts. Am J Physiol Cell Physiol 2007;292:C1830-6.

[35] Shapiro F. Variable conformation of gap junctions linking bone cells: a transmission electron microscopic study of linear, stacked linear, curvilinear, oval, and annular junctions. Calcif Tissue Int 1997;61:285-93.

[36] Yellowley CE, Li Z, Zhou Z, Jacobs CR, Donahue HJ. Functional gap junctions between osteocytic and osteoblastic cells. J Bone Miner Res 2000;15:209-17.

[37] Kato Y, Windle JJ, Koop BA, Mundy GR, Bonewald LF. Establishment of an osteocyte-like cell line, MLO-Y4. J Bone Miner Res 1997;12:2014-23.

[38] Guo XE, Takai E, Jiang X, Xu Q, Whitesides GM, Yardley JT, et al. Intracellular calcium waves in bone cell networks under single cell nanoindentation. Mol Cell Biomech 2006:3:95-107.

[39] Singhvi R, Kumar A, Lopez GP, Stephanopoulos GN, Wang DI, Whitesides GM, et al. Engineering cell shape and function. Science 1994;264:696-8.

[40] Godin LM, Suzuki S, Jacobs CR, Donahue HJ, Donahue SW. Mechanically induced intracellular calcium waves in osteoblasts demonstrate calcium fingerprints in bone cell mechanotransduction. Biomech Model Mechanobiol 2007;6:391-8.

[41] Norvell SM, Ponik SM, Bowen DK, Gerard R, Pavalko FM. Fluid shear stress induction of COX-2 protein and prostaglandin release in cultured MC3T3-E1 osteoblasts does not require intact microfilaments or microtubules. J Appl Physiol 2004;96: 957-66.

[42] Ralston SH, Todd D, Helfrich M, Benjamin N, Grabowski PS. Human osteoblast-like cells produce nitric oxide and express inducible nitric oxide synthase. Endocrinology 1994;135:330-6.

[43] Guo Y, Martinez-Williams C, Gilbert KA, Rannels DE. Inhibition of gap junction communication in alveolar epithelial cells by $18 \alpha$-glycyrrhetinic acid. Am J Physiol 1999;276:L1018-26.

[44] Yellowley CE, Jacobs CR, Donahue HJ. Mechanisms contributing to fluid-flow-induced $\mathrm{Ca}^{2+}$ mobilization in articular chondrocytes. J Cell Physiol 1999;180:402-8.

[45] Donahue SW, Donahue HJ, Jacobs CR. Osteoblastic cells have refractory periods for fluid-flow-induced intracellular calcium oscillations for short bouts of flow and display multiple low-magnitude oscillations during long-term flow. J Biomech 2003;36:35-43.

[46] Thompson WR, Majid AS, Czymmek KJ, Ruff AL, Garcia J, Duncan RL, et al. Association of the $\alpha_{2} \delta_{1}$ subunit with $\mathrm{Ca}_{\mathrm{v}} 3.2$ enhances membrane expression and regulates mechanically induced atp release in MLO-Y4 osteocytes. J Bone Miner Res 2011;26:2125-39.

[47] Ryder KD, Duncan RL. Parathyroid hormone enhances fluid shear-induced $\left[\mathrm{Ca}^{2+}\right]_{\mathrm{i}}$ signaling in osteoblastic cells through activation of mechanosensitive and voltage-sensitive $\mathrm{Ca}^{2+}$ channels. J Bone Miner Res 2001;16:240-8. 
[48] Ajubi NE, Klein-Nulend J, Alblas MJ, Burger EH, Nijweide PJ. Signal transduction pathways involved in fluid flow-induced $\mathrm{PGE}_{2}$ production by cultured osteocytes. Am J Physiol-Endoc M 1999;276:E171-8.

[49] Klein-Nulend J, Semeins CM, Ajubi NE, Nijweide PJ, Burger EH. Pulsating fluid flow increases nitric oxide (NO) synthesis by osteocytes but not periosteal fibroblastscorrelation with prostaglandin upregulation. Biochem Biophys Res Commun 1995;217:640-8.

[50] Smalt R, Mitchell FT, Howard RL Chambers TJ. Mechanotransduction in bone cells: induction of nitric oxide and prostaglandin synthesis by fluid shear stress, but not by mechanical strain. Adv Exp Med Biol 1997;433:311-4.

[51] Klein-Nulend J, Helfrich $\mathrm{MH}$, Sterck JG, MacPherson H, Joldersma M, Ralston $\mathrm{SH}$ et al. Nitric oxide response to shear stress by human bone cell cultures is endothelial nitric oxide synthase dependent. Biochem Biophys Res Commun 1998;250: 108-14.

[52] Kamioka H, Ishihara Y, Ris H, Murshid SA, Sugawara Y, Takano-Yamamoto T, et al Primary cultures of chick osteocytes retain functional gap junctions between osteocytes and between osteocytes and osteoblasts. Microsc Microanal 2007;13: 108-17.

[53] Chan ME, Lu XL, Huo B, Baik AD, Chiang V, Guldberg RE, et al. A trabecular bone explant model of osteocyte-osteoblast co-culture for bone mechanobiology. Cell Mol Bioeng 2009;2:405-15.

[54] Robling AG, Castillo AB, Turner $\mathrm{CH}$. Biomechanical and molecular regulation of bone remodeling. Annu Rev Biomed Eng 2006;8:455-98.

[55] Robling AG, Burr DB, Turner $\mathrm{CH}$. Recovery periods restore mechanosensitivity to dynamically loaded bone. J Exp Biol 2001;204:3389-99.

[56] Umemura Y, Ishiko T, Yamauchi T, Kurono M, Mashiko S. Five jumps per day increase bone mass and breaking force in rats. J Bone Miner Res 1997:12:1480-5.

[57] Baik AD, Lu XL, Qiu J, Huo B, Hillman EM, Dong C, et al. Quasi-3D cytoskeletal dynamics of osteocytes under fluid flow. Biophys J 2010;99:2812-20.

[58] Pavalko FM, Chen NX, Turner CH, Burr DB, Atkinson S, Hsieh YF, et al. Fluid shear-induced mechanical signaling in MC3T3-E1 osteoblasts requires cytoskeleton-integrin interactions. Am J Physiol 1998;275:C1591-601. 